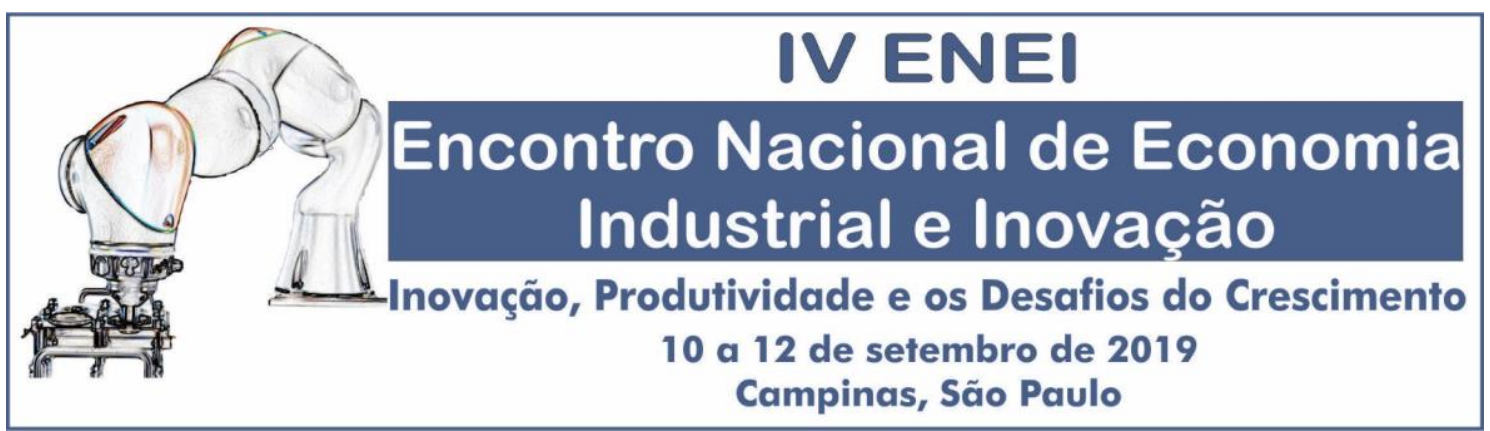

A Petrobras como agente do desenvolvimento produtivo no Brasil: importância e esvaziamento

\author{
Marcelo Sartorio Loural ${ }^{1}$ \\ Cássio Garcia Ribeiro Soares da Silva ${ }^{2}$ \\ Valéria Silva Mortari ${ }^{3}$
}

\begin{abstract}
Resumo: Em diversos momentos a Petrobras foi utilizada pelo governo brasileiro como mecanismo indutor do desenvolvimento do país, dado o poder de arraste de seus investimentos e demandas sobre a economia doméstica. Essa faceta foi marcante durante os governos Lula e Dilma. Contudo, a partir do governo Temer observa-se uma reorientação na estratégia de atuação da Petrobras, da qual os desinvestimentos e a alteração na política de conteúdo local são evidências. O objetivo deste trabalho é mostrar a Petrobras como agente de desenvolvimento produtivo até 2015 e a descontinuidade dessa política desde então. Para entender a importância das atividades do setor para a economia do país é empregado o método de análise insumo-produto, com base do cálculo de seus índices de ligação e multiplicadores de emprego e produto. Os resultados evidenciam o papel desempenhado pela Petrobras em termos de encadeamentos e seu potencial de geração de produto e emprego.
\end{abstract}

Palavras-chave: Petrobrás; encadeamentos; insumo-produto.

Abstract: At various times Petrobras was used by the Brazilian government as a means to induce economic development, given the dragging power of its investments and demands on the domestic economy. This aspect was remarkable during the Lula and Dilma governments. However, since Temer government, there is a reorientation of Petrobras' strategies, which are evidenced by the divestments and changes in the local content policy. The objective of this paper is to show Petrobras as a productive development agent until 2015 and the discontinuity of this policy since then. In order to understand the importance of the sector's activities for the country's economy, the inputoutput analysis is used, based on the calculation of its linkage indexes and multipliers of employment and output. The results show the role played by Petrobras in terms of linkages and its potential for product and employment generation.

Key-words: Petrobras; linkages; input-output.

Área ABEIN: 1.1 (Indústria e Competitividade - Dinâmicas industriais setoriais e dos sistemas de produção)

Classificação JEL: L38 (Nonprofit Organizations and Public Enterprise - Public Policy)

\footnotetext{
${ }^{1}$ Professor do Instituto de Economia e Relações Internacionais da Universidade Federal de Uberlândia.

2 Professor do Instituto de Economia e Relações Internacionais da Universidade Federal de Uberlândia.

${ }^{3}$ Doutoranda em Economia na Universidade Federal do Paraná e bolsista CAPES.
} 


\title{
A Petrobras como agente do desenvolvimento produtivo no Brasil: importância e
}

\author{
esvaziamento
}

\section{Introdução}

A Petrobras foi criada pelo governo federal do Brasil em 1953, com o objetivo de reduzir as restrições ao processo de industrialização do país, em vista das limitações em termos de recursos petrolíferos. Seis décadas após sua criação, a estatal brasileira é uma empresa posicionada entre as grandes companhias de petróleo do mundo e reconhecida internacionalmente por sua capacitação tecnológica em águas profundas. A descoberta do pré-sal representa prova inequívoca dessa capacitação. Ademais, convém ressaltar que no ano de 2014 a Petrobras se tornou a maior produtora de petróleo entre as empresas de capital aberto, quando ultrapassou a Exxon.

Apesar da quebra do monopólio em 1997, a Petrobras manteve sua soberania no mercado brasileiro, com uma participação bastante significativa em todas as etapas da cadeia produtiva do petróleo e gás do país. Além do seu papel proeminente na área de Exploração e Produção (E\&P), trata-se da empresa com maior participação na etapa downstream. Logo, seguindo a tendência hegemônica entre as grandes companhias de petróleo, a Petrobras é uma empresa verticalmente integrada, com atuação importante em todos os elos da cadeia de petróleo e gás. Assim, trata-se de um autêntico caso de petrolífera com atuação do poço ao posto.

Durante boa parte de sua existência a Petrobras foi utilizada pelo governo brasileiro como mecanismo indutor do desenvolvimento do país. Tal faceta da empresa foi marcante durante os governos petistas. Salta aos olhos os impactos dos investimentos da empresa e da política de conteúdo local sobre a economia do país, especialmente no que diz respeito à indústria para-petroleira, durante esse período.

Com a deposição de Dilma e a ascensão de Michel Temer à Presidência da República há sinais inequívocos de uma guinada conservadora na agenda do governo voltada para o setor petrolífero, com a mudança da percepção acerca dos papéis assumidos pela Petrobras. Pode-se afirmar que essa guinada conservadora mostra sinais de permanência no governo de Jair Bolsonaro. As principais modificações na política brasileira voltada para o setor petrolífero e concernentes à Petrobras vis-à-vis os governos petistas são as seguintes: desinvestimentos, priorização dos acionistas e redução das exigências em termos de conteúdo local.

O objetivo deste trabalho é revelar como a Petrobras foi utilizada como agente de desenvolvimento produtivo durante os governos petistas, bem como a descontinuidade dessa política e seus desdobramentos após o impeachment da Presidenta Dilma Rousseff. O presente estudo se justifica por vários motivos, entre os quais é possível destacar: i) a estatal brasileira é uma das mais importantes companhias de petróleo do mundo; ii) a Petrobras é uma empresa estatal estratégica para o desenvolvimento do país, com uma participação importante na formação bruta do capital fixo brasileiro; iii) ainda que o Brasil possua uma matriz energética diversificada, com uma participação importante de energias "limpas" (como a hidroeletricidade), o petróleo tem e continuará tendo um peso importante na matriz energética (brasileira e mundial), o que justifica a realização do estudo; iv) o pré-sal representa a maior descoberta de petróleo realizada nos últimos tempos. 
Este artigo se apoia em revisão bibliográfica, pesquisa documental e coleta e análise de dados secundários. A revisão da bibliográfica se debruça sobre a literatura concernente a temas como Estado, políticas setoriais e desenvolvimento da estrutura produtiva. A pesquisa documental foi construída a partir de relatórios da Petrobras e da Agência Nacional do Petróleo (ANP). Por fim, no que se refere à coleta e análise de dados secundários, este artigo se apoio em dados da Economática, Pesquisa Industrial Anual (PIA/IBGE) e Relatório Anual de Informações Sociais. Além disso, com vistas a revelar a importância das atividades de exploração e produção e refino para a economia do país é empregado o método de análise insumo-produto, em termos de encadeamentos produtivos, com base do cálculo de seus índices de ligação, multiplicador de emprego e produto, é empregado.

Os resultados deste estudo evidenciam o importante papel desempenhado pelo setor de petróleo, com destaque para a Petrobras, do ponto de vista do potencial de realização de investimentos autônomos e também de indução a setores encadeados. Ademais, com base no método insumo-produto, foi possível identificar um elevado multiplicador de emprego, de produção e índice de ligação a jusante das áreas em que a empresa atua.

Desse modo, o artigo aborda três aspectos que mostram a importância da Petrobrás para a economia brasileira: 1) a capacidade, de forma autônoma, de puxar os investimentos industriais; 2) o estímulo a fornecedores locais para Exploração e Produção (E\&P) através da Política de Conteúdo Local; 3) os encadeamentos, especialmente a jusante, das atividades de refino. Após a seção 2, que traz o embasamento teórico do artigo, as seções seguintes detalharão os três aspectos citados.

\section{Estado, políticas setoriais e desenvolvimento da estrutura produtiva}

No último capítulo de sua principal obra, a Teoria Geral do Emprego do Juro e da Moeda, Keynes $\left(1992^{4}\right)$ discorre sobre a atuação do Estado na economia como forma de lidar com dois problemas essenciais enfrentados pelas economias capitalistas: sua incapacidade para proporcionar o pleno emprego e a desigualdade na distribuição da riqueza e da renda.

A incapacidade de uma economia capitalista lidar com os referidos problemas se origina, segundo o autor em questão, da instabilidade estrutural do capitalismo decorrente da existência de formas de alocação da riqueza privada distintas do investimento produtivo que cumprem sua função de valorização sem necessariamente gerar postos de trabalho.

A decisão de investir se dá, na visão de Keynes, a partir da comparação entre o retorno esperado do investimento, a Eficiência Marginal do Capital (EMgC) e a taxa de juros, que representaria o retorno de uma aplicação financeira. O cálculo da EMgC é algo de grande complexidade na teoria keynesiana, uma vez que se considera um ambiente marcado pela incerteza. Espera-se uma determinada taxa de retorno de investimento tendo como base a demanda em períodos anteriores. Contudo, considerando que o futuro não será necessariamente uma reprodução do passado, esse cálculo se torna, de certo modo, precário. Portanto, o a decisão de investir se dá, na visão de Keynes, com base em uma comparação cujo cálculo é muito impreciso. Isso faz com que o investimento seja bastante

\footnotetext{
${ }^{4}$ Original de 1936.
} 
instável e tal instabilidade se reflita na economia como um todo, dada a estabilidade do consumo e sua dependência em relação ao nível de renda.

Dentro dessa lógica, investimentos produtivos constituem uma das opções, não a única, de valorização da riqueza em uma economia capitalista. Considerando a incerteza quanto ao futuro, ponto marcante em uma abordagem keynesiana, os agentes capitalistas tendem a preferir maneiras mais líquidas para a valorização de seus ativos, como, por exemplo, as aplicações financeiras.

Dessa forma, Keynes considera que o investimento, por seu potencial de geração de postos de trabalho e sua instabilidade, é demasiadamente importante para ficar a cargo somente do setor privado, cabendo ao Estado conferir certa estabilidade ao ciclo econômico, evitando flutuações e garantindo maior previsibilidade às decisões privadas de investir e empregar.

Cabe ressaltar que na visão de Keynes o investimento público tem papel estratégico e não deve tomar um espaço que possa ser ocupado pelo setor privado. Esse argumento é, inclusive, citado por Mazzucato (2013):

The important thing for Government is not to do things which individuals are doing already, and to do them a little better or a little worse; but to do those things which at present are not done at all. (Keynes, 1926 - apud Mazzucato, 2013: 2)

Em outros termos, o investimento estatal deve atuar de forma complementar ao investimento privado e em atividades o facilitem, como melhorias na infraestrutura, por exemplo.

Nesse sentido, Mazzucato (2013) discorre sobre o "Estado Empreendedor", com ênfase na apropriação pelo setor privado de tecnologias e investimentos realizados por órgãos públicos, sendo estes fundamentais para o desenvolvimento produtivo $\mathrm{e}$ tecnológico dos Estados Unidos no século XX em especial.

No que diz respeito ao Estado como formulador de estratégias de desenvolvimento econômico, Hirschman (1958) discorre que a razão fundamental para alguns países se encontrarem em situação de subdesenvolvimento não é a escassez de fatores de produção (capital e trabalho), como enunciava a teoria econômica convencional. Para o autor, os países subdesenvolvidos dispunham dos recursos necessários e de capacidade empresarial para se desenvolver, faltando para isso a adoção da estratégia correta.

Tal estratégia, segundo o autor, passaria pela identificação de setores específicos com grande potencial de encadeamento produtivo, tanto para trás, como demandantes, quanto para a frente, como fornecedores de insumos. Esses seriam chamados de setoreschave. Para Hirschman (1958), a atuação do Estado na condução da política de desenvolvimento produtivo deveria se concentrar nesses setores, proporcionando um crescimento desequilibrado. Para o autor, tais desequilíbrio seriam compensados com a indução a investimentos dos setores encadeados.

Segundo Hirschman (1958), a teoria econômica aponta para o papel do investimento como gerador de emprego e renda, mas muitas vezes deixa de considerar tal gasto como indutor de novas inversões, o que o autor chama de "investimentos adicionais". Desse modo, pode-se dividir os investimentos em duas categorias: o autônomo, que vem à frente da demanda, e o induzido, que responde a uma demanda adicional, seja por parte de consumidores ou por setores que estão à frente na cadeia produtiva. É essencial que setores-chave, com grande potencial de encadeamento, exerçam esse papel de investidores autônomos, guiados pela política estatal de desenvolvimento. 
Nesse sentido, o setor de petróleo, com destaque para a Petrobras, apresenta esse potencial de realização de investimentos autônomos e também de indução a setores encadeados, conforme abordaremos nas seções seguintes.

\section{Petrobras como agente do investimento autônomo}

Um dos fatores pelos quais a Petrobras se apresenta como uma importante dinamizadora do crescimento econômico e do desenvolvimento da estrutura produtiva é o fato da empresa ser responsável por uma parcela considerável dos investimentos realizados na economia brasileira desde meados da década de 2000. Tal processo sobre uma interrupção em 2014 por conta de aspectos ligados a um maior nível de endividamento e investigações de corrupção.

É importante destacar que, em especial no âmbito do pré-sal, a Petrobras, aparece como uma fonte de investimento autônomo, isto é, o gasto com ampliação de capacidade produtiva que acontece mesmo à frente da demanda e pode potencializar um ciclo expansivo na economia.

\section{Gráfico 1 - Taxa de investimento - extração e refino de petróleo e total da indústria brasileira, 2007 a 2017}

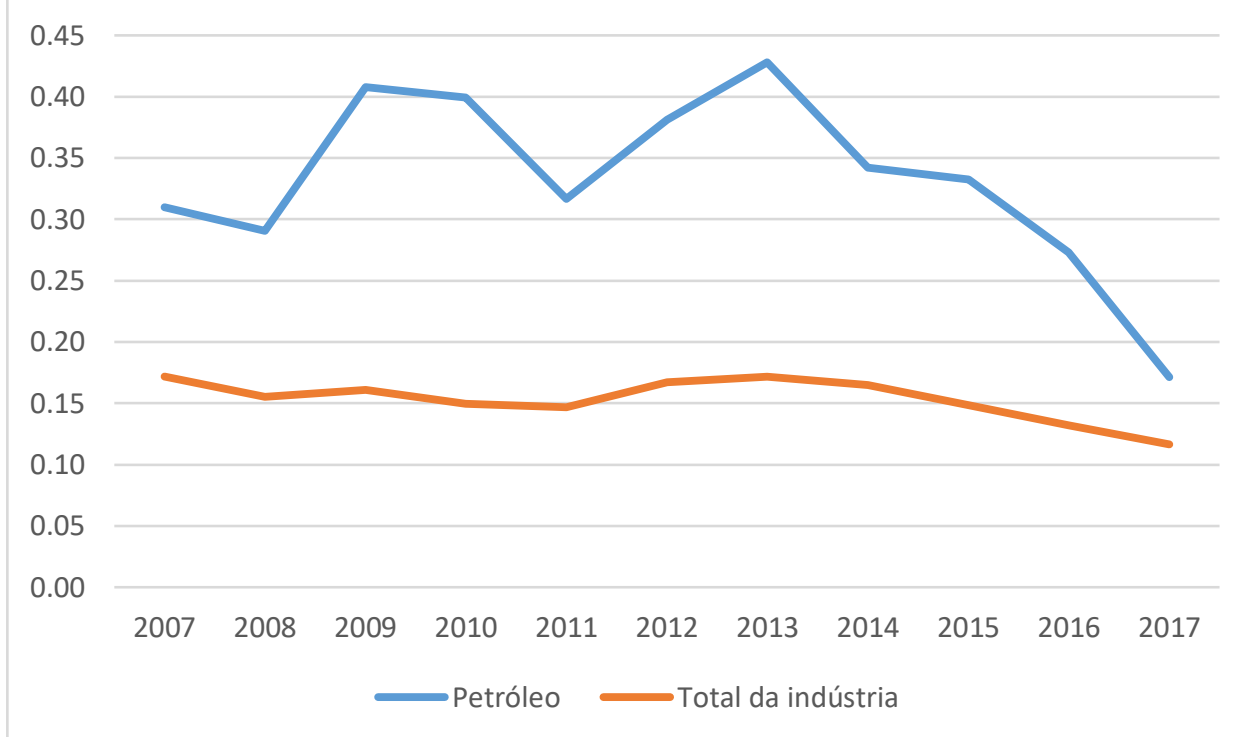

Fonte: Elaboração própria a partir da PIA/IBGE

Os gráficos 1 e 2 dão a dimensão de tal importância. No Gráfico 1 é apresentada a taxa de investimento, medida aqui pela razão entre os gastos com aquisição de ativo imobilizado e o Valor da Transformação Industrial (VTI) ${ }^{5}$, para o setor petroleiro (extração e refino somados) e para o total da indústria brasileira. Nota-se que em todo o período de 2007 a 2017 a taxa de investimento do setor petroleiro é maior que a média da indústria, puxando tal média para cima. Enquanto no total da indústria o investimento não representa mais que $17 \%$ de seu valor adicionado, no setor de petróleo (do qual a Petrobras representa quase a totalidade) chegou a apresentar picos de mais de $40 \%$, caindo para a faixa dos 30\% em 2014 e 2015 e para menos de $20 \%$ em 2016 e 2017, ainda assim situando-se muito acima dos demais. Cabe ressaltar que o setor de petróleo representa

\footnotetext{
${ }^{5}$ Entende-se aqui este indicador como uma proxy setorial da taxa de investimento.
} 
cerca de $15 \%$ do VTI da indústria brasileira, de acordo com a Pesquisa Industrial Anual (PIA/IBGE).

Os dados expressos no Gráfico 2 complementam a análise iniciada acima. Percebe-se que, mesmo com a redução dos investimentos do setor de petróleo, sua participação no total das inversões da indústria brasileira permanece acima de $30 \%$ até 2016, com uma queda maior em 2017, chegando a 24\%. Ainda assim, a importância do setor é evidente, representando um quarto do total dos investimentos da indústria brasileira. Percebe-se que, mesmo com a queda apresentada pelo setor de petróleo, os demais setores também mostram trajetórias descendentes, uma vez que a proporção só vem a cair em 2017.

\section{Gráfico 2 - Participação dos setores de extração e refino de petróleo no total dos investimentos industriais e aquisição líquida de ativo imobilizado pela Petrobras, 2007 a 2018}

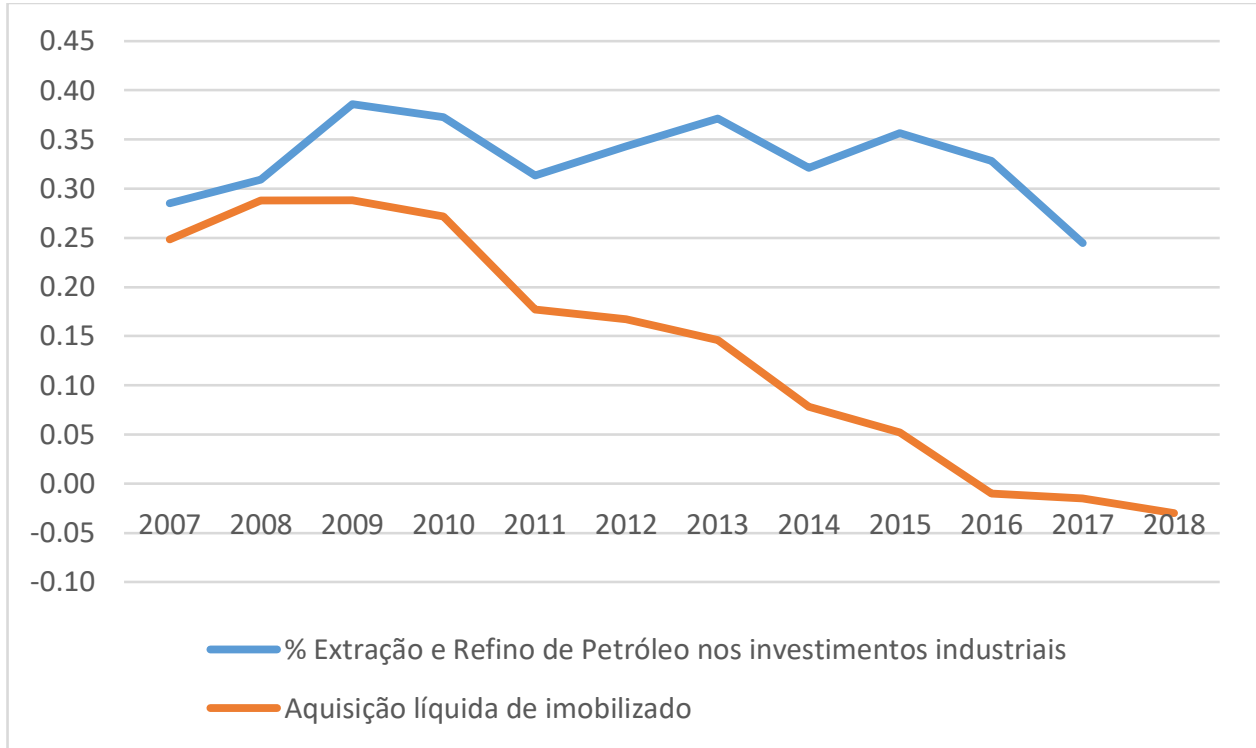

Fonte: Elaboração própria a partir da PIA/IBGE e da Economática

O outro indicador mostrado no Gráfico 2 é a aquisição líquida de ativo imobilizado ${ }^{6}$ por parte da Petrobras, empresa que detém mais de $90 \%$ do setor em questão. Se em 2009 e 2010 a Petrobras adicionou por volta de $30 \%$ ao seu estoque de ativo imobilizado, esse valor decresce de maneira vertiginosa após 2013, chegando a patamares negativos a partir de 2016, chegando a uma perda líquida de $3 \%$ do total de seu imobilizado em 2018. Esses dados mostram uma clara reorientação da empresa a partir de 2014, com revisões nas suas decisões de investimento. Após 2016, não há somente uma redução dos investimentos, sendo presente também uma política deliberada de desinvestimento, algo que se reflete no indicador em questão. Essa conclusão é referendada pela própria empresa, em seus mais recentes relatórios anuais, em que a

\footnotetext{
${ }^{6}$ Aquisição líquida de imobilizado: constrói-se este indicador a partir de informações do Demonstrativo de Fluxo de Caixa e do ativo. No numerador contabilizam-se os gastos com aquisição e ativos fixos e diferido subtraindo a depreciação e as vendas de ativos fixos. No denominador é colocado o estoque de imobilizado e diferido da empresa. O indicador mostra, portanto, a porcentagem do ativo imobilizado que foi efetivamente adicionada ao estoque no ano, já descontando eventuais vendas e a reposição da depreciação. Assim, é possível se ter uma ideia dos investimentos que realmente adicionaram capacidade de produção e de geração de empregos e daqueles que se referem apenas à modernização da capacidade existente.
} 
estratégia de desinvestimento aparece como um dos pilares para redução do endividamento da companhia:

\begin{abstract}
Os quatro outros pilares se integram para permitir a redução do nosso endividamento: (1) uma nova política de preços para a gasolina e o diesel, baseada na paridade internacional e com a definição de que, em nenhum momento estaremos praticando preços abaixo da paridade internacional; (2) maior eficiência em nossos investimentos, traduzindo-se em redução de nossos investimentos com aumento de nossa produção; (3) redução de nossos custos, também sem qualquer prejuízo à nossa segurança e aos nossos objetivos de produção; e (4) realização de parcerias e desinvestimentos com transações que totalizem US\$ 21 bilhões no biênio 2017/18. (Petrobras, 2016: 8)
\end{abstract}

Nos dois gráficos é possível perceber a substancial queda dos investimentos realizados pelo setor de petróleo a partir de 2014. Dada a relevância do setor em questão para a indústria brasileira, essa redução leva a significativos impactos macroeconômicos, evidenciados pela trajetória declinante do investimento nos anos em questão. Mesmo em se levando em conta a existência de um estoque de dívidas assumido no momento da expansão dos investimentos e as dificuldades de se obter novos montantes de recursos de terceiros, a estratégia de desinvestimentos leva a uma destruição do potencial da empresa em voltar a alavancar as inversões na economia brasileira em um futuro próximo, mesmo com as finanças em melhor situação.

\title{
4. Política de conteúdo local
}

A Petrobras, ao longo de sua trajetória, foi um importante instrumento de política pública, seja no sentido da busca pela autossuficiência brasileira em óleo cru e refinado, seja no desenvolvimento da indústria para-petroleira local. Especificamente em relação ao desenvolvimento do parque de fornecedores doméstico, desde seus primeiros empreendimentos a petrolífera brasileira ajudou a erguer tal parque. Segundo Villela (1984) a petrolífera brasileira foi a primeira estatal do país a adotar uma política de compras direcionada ao mercado doméstico.

Ainda sob a égide do modelo de industrialização por substituição de importações, as restrições de divisas e a instabilidade cambial tornavam proibitivo à petrolífera brasileira fazer suas encomendas nos mercados externos. Assim, a Petrobras passou a investir no parque industrial local "responsável pelo suprimento de materiais, equipamentos, assim como no fortalecimento da capacitação em projeto, engenharia e tecnologia" (Marzani et alli, 2003). Os dados demonstram que o empenho da Petrobras trouxe frutos importantes.

Nos primórdios, o índice de nacionalização das compras da estatal brasileira era de cerca de 10\% (ANP, 1999). Com vistas a reduzir sua dependência em relação aos materiais, equipamentos e serviços importados a Petrobras colocou em marcha uma série de políticas, com vistas a de capacitar e qualificar o parque de fornecedores locais. Os dados demonstram que seu empenho trouxe frutos importantes. Nas obras das refinarias Gabriel Passos e Alberto Pasqualini, inauguradas em 1968, um índice de aquisições internas da ordem de $80 \%$ foi alcançado. Em meados da década de 1980, são descobertos grandes reservatórios de petróleo localizados em águas profundas. Inicialmente uma parte importante dos equipamentos e serviços utilizados nessa nova fronteira exploratória foi 
adquirida no exterior, o que levou a um recuo no índice de compras, que foi para $52 \%$ em 1980. No entanto, em apenas três anos tal índice retornou para o patamar de $80 \%$ (ANP, 1999).

A implementação do receituário neoliberal pelo governo brasileiro durante os anos 1990 modificou o padrão de intervenção do Estado brasileiro no setor petrolífero. A quebra do monopólio da Petrobras nas atividades de exploração, produção, transporte, refino, importação e exportação, é o principal resultado dessa modificação. O novo ambiente regulatório e macroeconômico (caracterizado pelo binômio abertura comercial e câmbio apreciado - durante o primeiro mandato de FHC) estimulou a Petrobras a se aproximar de parceiros estrangeiros. Diante desse quadro e em virtude da grande dependência dos fornecedores brasileiros em relação às encomendas da Petrobras, deflagrou-se uma profunda crise no parque de fornecedores doméstico, contexto no qual falências e desnacionalizações entre as empresas do setor ocorreram com frequência (Furtado et al., 2003).

Tabela 1 - Conteúdo local médio estabelecido nas rodadas de licitações da ANP

\begin{tabular}{ccc}
\hline & CONTEÚDO LOCAL MÉDIO - & CONTEÚDO LOCAL MÉDIO - ETAPA \\
ETAPA DE EXPLORAÇÃO & DE DESENVOLVIMENTO \\
\hline R1 (1999) & $25 \%$ & $27 \%$ \\
R2 (2000) & $42 \%$ & $48 \%$ \\
R3 (2001) & $28 \%$ & $40 \%$ \\
R4 (2002) & $39 \%$ & $54 \%$ \\
R5 (2003) & $78,8 \%$ & $85,6 \%$ \\
R6 (2004) & $85,7 \%$ & $88,8 \%$ \\
R7 (2005) & $74 \%$ & $81 \%$ \\
R9 (2007) & $68,9 \%$ & $76,5 \%$ \\
R10(2008) & $79 \%$ & $84 \%$ \\
R11 (2013) & $61,5 \%$ & $75,6 \%$ \\
R12(2013) & $72,6 \%$ & $84,5 \%$ \\
\hline
\end{tabular}

Fonte: elaboração própria a partir de ANP (2018).

A crise no parque de fornecedores doméstico pode ser considerada o principal motivador para o início da adoção dos critérios de conteúdo local nos leilões realizados pela ANP. Tal política se inicia de maneira tímida ainda no governo FHC. Todavia, a partir do governo Lula, a política de conteúdo local se torna um dos principais instrumentos de política industrial do país. Os dados da Tabela 1 evidenciam que os requisitos de conteúdo local nas etapas de exploração e desenvolvimento e produção aumentaram de maneira expressiva entre o governo FHC e os governos petistas.

Cumpre ressaltar que o compromisso da petrolífera brasileira com conteúdo local nesse período não se restringia a cumprir as exigências regulatórias da ANP, visto que tal empresa também adotou metas em termos de conteúdo local para atividades não ligados à $\mathrm{E} \& \mathrm{P}$, como transporte e refino. A Petrobras elevou os índices de conteúdo local em todos os investimentos por ela realizados entre 2003 e 2009 , de $57 \%$ para $75 \%$, respectivamente (Petrobras, 2010). Em 2011, a companhia de petróleo brasileira elaborou sua própria política de conteúdo local, "padronizando procedimentos e adotando metas autoimpostas em todas as outras áreas de operação" (Almeida, Lima-de-Oliveira e Schneider, 2013, p. 38). 
Tabela 2 - Emprego formal e VTI na indústria parapetroleira (2003 - 2017)

\begin{tabular}{|c|c|c|c|c|c|c|c|c|}
\hline \multirow[t]{2}{*}{ ANO } & \multicolumn{2}{|c|}{$\begin{array}{c}\text { Atividades de apoio à } \\
\text { extração de petróleo e gás } \\
\text { natural }\end{array}$} & \multicolumn{2}{|c|}{$\begin{array}{c}\text { Fabricação de } \\
\text { máquinas e } \\
\text { equipamentos para a } \\
\text { prospecção e extração } \\
\text { de petróleo }\end{array}$} & \multicolumn{2}{|c|}{$\begin{array}{c}\text { Construção de } \\
\text { embarcações e } \\
\text { estruturas flutuantes }\end{array}$} & \multicolumn{2}{|c|}{ TOTAL } \\
\hline & $\begin{array}{c}\text { Estoque } \\
\text { de } \\
\text { emprego }\end{array}$ & VTI & $\begin{array}{l}\text { Estoque } \\
\text { de } \\
\text { emprego }\end{array}$ & VTI & $\begin{array}{l}\text { Estoque } \\
\text { de } \\
\text { emprego }\end{array}$ & VTI & $\begin{array}{c}\text { Estoque } \\
\text { de } \\
\text { emprego }\end{array}$ & VTI \\
\hline 2003 & 8489 & 24.83 .426 & 2840 & 734.334 & 14394 & 2.035 .807 & 25723 & 5.253 .567 \\
\hline 2004 & 8635 & 3.473 .445 & 4672 & 688.153 & 16993 & 2.482 .053 & 30300 & 6.643 .651 \\
\hline 2005 & 9692 & 3.136 .395 & 5154 & 1.082 .638 & 19312 & 2.126 .005 & 34158 & 6.345 .038 \\
\hline 2006 & 27910 & 3.423 .619 & 4994 & 837.281 & 22956 & 8.372 .801 & 55860 & 12.633 .701 \\
\hline 2007 & 25976 & 4.197 .586 & 5160 & 1.156 .501 & 23306 & 2.514 .733 & 54442 & 7.868 .820 \\
\hline 2008 & 36066 & 6.185 .620 & 6975 & 1.373 .092 & 26970 & 2.685 .123 & 70011 & 10.243 .835 \\
\hline 2009 & 39910 & 7.871 .219 & 6488 & 1.451 .173 & 29448 & 3.545 .337 & 75846 & 12.867 .729 \\
\hline 2010 & 22427 & & 6095 & 1.930 .830 & 34341 & 3.609 .640 & 62863 & 5.540 .470 \\
\hline 2011 & 25875 & 10.652 .728 & 7384 & 1.844 .684 & 36563 & 4.348 .853 & 69822 & 16.846 .265 \\
\hline 2012 & 30234 & 12.378 .047 & 8038 & 2.014 .998 & 47529 & 5.100 .561 & 85801 & 19.493 .606 \\
\hline 2013 & 28830 & 10.987.238 & 8241 & 2.004 .854 & 52892 & 6.847 .585 & 89963 & 19.839 .677 \\
\hline 2014 & 30016 & 12.576 .363 & 8748 & 2.366 .499 & 52832 & 8.309 .001 & 91596 & 23.251 .863 \\
\hline 2015 & 26096 & 13.413 .826 & 10719 & 3.097 .800 & 42773 & 6.822 .019 & 79588 & 9.919 .819 \\
\hline 2016 & 19539 & 7.952 .097 & 8843 & 1.962 .541 & 32411 & 4.900 .511 & 60793 & 14.815 .149 \\
\hline 2017 & 18647 & 7.383 .857 & 8185 & 1.458 .286 & 25557 & 3.908 .535 & 52389 & 12.750 .678 \\
\hline
\end{tabular}

Fonte: Fonte: Elaboração própria a partir da RAIS/TEM e PIA/IBGE

* Em R\$ 1.000,00. Valores monetários corrigidos pelo IPCA $(2017=100)$.

Pode-se dizer que a política de conteúdo local o desenvolvimento dos fornecedores do país, sobretudo na área de E\&P, trazendo à tona benefícios como os ganhos em termos tecnológicos a esses fornecedores (Gall, 2011; Dantas e Bell, 2011). Quanto ao potencial de encadeamento dessa política, a Tabela mostra o volume de emprego formal nas atividades auxiliares à exploração de petróleo, a saber: fabricação de máquinas e equipamentos para a prospecção e extração de petróleo; atividades de apoio à extração de petróleo e gás natural; construção de embarcações e estruturas flutuantes. Entende-se que estas sejam as atividades afetadas diretamente pela atividade da Petrobras.

Entre 2003 (primeiro ano do governo Lula) e 2014 (último ano do primeiro mandato do governo Dilma) o emprego formal na indústria parapetroleira do país mais do que triplicou, saltando de 25.723 para 91.596. No que diz respeito ao VTI o crescimento foi ainda mais expressivo, passando de $\mathrm{R} \$ 5,2$ bilhões para $\mathrm{R} \$ 23,2$ bilhões nesse mesmo período. Nos últimos três anos da série pode-se perceber uma queda tanto no estoque de emprego formal, como no VTI da indústria para-petroleira do país. Tal queda pode ser explicada pela crise recente da Petrobras, mas também pela alteração na política de conteúdo local a partir do governo Temer.

Com a deposição de Dilma e a ascensão de Michel Temer à Presidência da República há sinais inequívocos de uma guinada conservadora na agenda do governo voltada para o setor petrolífero, com a mudança da percepção acerca dos papéis assumidos pela Petrobras. Entre as modificações na política brasileira voltada para o setor petrolífero e concernentes à Petrobras vis-à-vis os governos petistas está a redução das exigências em termos de conteúdo local. A partir da Resolução n ${ }^{\circ}$ 07/2017 do Conselho Nacional de Política Energética, ficou definido o novo modelo de conteúdo local a ser adotado nas rodadas de licitação da ANP. Além de deixar de ser considerado como fator de pontuação das ofertas houve uma redução dos percentuais mínimos de conteúdo local.

O Presidente da Petrobras à época, Pedro Parente, declarou que tal medida deveria ser comemorada, uma vez que tira da petrolífera brasileira a indústria de fornecedores do 
país e que essa incumbência “deveria ser das políticas públicas”. Parente criticou a política de conteúdo local anteriormente em vigor, avaliando-a como incompatível com a capacidade de fornecimento da indústria para-petroleira do país. Nesse sentido, segundo o ex-dirigente da empresa, o país precisa de uma política de conteúdo local que "emancipe a indústria nacional, ao invés de fazê-la viciada numa reserva de mercado" (Ramalho e Polito, 2017).

A Tabela 3 evidencia o recuo no índice de conteúdo local entre a rodada 13 (ainda primeiro ano do segundo governo Dilma) e a rodada 14 (já no governo Temer).

Tabela 3 - Conteúdo local médio estabelecido nas rodadas de licitações da ANP

\begin{tabular}{ccc} 
& CONTEÚDO LOCAL MÉDIO - & CONTEÚDO LOCAL MÉDIO - ETAPA \\
& ETAPA DE EXPLORAÇÃO & DE DESENVOLVIMENTO \\
\hline R13 (2015) & $73,1 \%$ & $79,5 \%$ \\
R14 (2017) & $38,8 \%$ & $42 \%$ \\
\hline
\end{tabular}

Fonte: elaboração própria a partir de ANP (2018).

Pode-se afirmar que com a eleição do Presidente Jair Bolsonaro essa interpretação crítica acerca da política de conteúdo local foi mantida. Prova disso é o fato que o escolhido por Bolsonaro para presidir a Petrobras, Roberto Castello Branco, em 2015, quando fazia parte do conselho de administração da empresa, deu a seguinte declaração à imprensa: "A Petrobras se viu diante de um problema de transferir recursos via conteúdo local mínimo para a indústria naval, de construção civil e fornecedores de equipamentos. Isso criou as condições para a formação de um cartel com corrupção" (Reuters, 2015).

\section{Petrobras e seus encadeamentos}

\subsection{Metodologia de análise}

Para analisar a capacidade de transbordamento do setor de refino de petróleo em termos de emprego e produção, a abordagem que segue parte da análise de insumoproduto.

A Matriz Insumo-Produto (MIP) descreve a economia em termos de circulação, descrevendo-a como um sistema integrado de fluxos e transferências de insumos e produtos intersetoriais, sendo ela composta pela conta de produção global e é dividida em três partes. A primeira retrata a demanda intermediária, isto é, as transações de compra e venda entre os setores produtivos. A segunda é composta pelo valor adicionado, que compreende a remuneração dos fatores e o excedente bruto operacional, os impostos e subsídios incidentes sobre a produção e as importações. A demanda final, a terceira parte da MIP, é composta pelo consumo das famílias e do governo, da formação bruta de capital e das exportações.

A partir da matriz de consumo intermediário, pode-se obter a matriz de coeficientes técnicos $(A)$, que é dada por:

$$
A=\left[a_{i j}\right] \text { em que } a_{i j}=\frac{X_{i j}}{X_{j}} \text { ou } X_{i j}=a_{i j} X_{j}
$$

$\mathrm{Na}$ equação acima, $a_{i j}$ representa o valor do insumo proveniente do setor i utilizado pelo setor j por unidade monetária, neste sentido, $X_{j}$ descreve o valor bruto da produção do setor $\mathrm{j}$. 
Sabendo que Y corresponde a demanda final da economia (consumo das famílias, consumo do governo, exportação e formação bruta de capital fixo) tem-se para cada linha da MIP, tem-se, então, que:

$$
\sum_{j=1}^{n} X_{i j}+Y_{i}=X_{i}=\sum_{j=1}^{n} a_{i j} X_{j}+Y_{i}
$$
se:

Em termos matriciais, $\mathrm{AX}+\mathrm{Y}=\mathrm{X}$. Com algumas operações matriciais, obtém-

$$
X=(I-A)^{-1} Y \text { ou } X=B Y
$$

em que I é uma matriz identidade e $(I-A)^{-1}=B=[b i j]$ é a matriz inversa de Leontief, em que cada elemento bij, segundo Guilhoto (2004), representa os requisitos diretos e indiretos de insumos do setor i por unidade de demanda final na produção do setor j. A equação (3) descreve o modelo básico de Leontief.

Tomando como ponto de partida o modelo básico de Leontief e tendo em vista Rasmussem (1956) e Hirschman (1958) é possível calcular os índices de ligação para trás que permitem analisar a capacidade de encadeamento dos setores em sua cadeia produtiva (GUILHOTO, 2004). Desta forma, a partir dos elementos da matriz inversa de Leontief definidos como $b_{i j}$ tem-se:

$$
I L T_{j}=\frac{1 / n \sum_{i=1}^{n} b_{i j}}{1 / n^{2} \sum_{i=1}^{n} \sum_{j=1}^{n} b_{i j}}
$$

Quanto ao índice de ligação para frente será empregado a metodologia de Ghosh a qual demonstra a importância de cada setor como fornecedor de insumos ao restante da economia. Considerando a matriz $\mathrm{K}$ :

$$
K=(\hat{X})^{-1} Z \text { em que } \quad K_{i j}=\frac{z_{i j}}{x_{i}}
$$

Pode-se definir a matriz G como:

$$
G=(I-K)^{-1}
$$
Ghosh:

Assim, pelos elementos da matriz G chega-se ao índice de ligação para frente de

$$
I L F_{i}=\frac{1 / n \sum_{j=1}^{n} g_{i j}}{1 / n^{2} \sum_{i=1}^{n} \sum_{j=1}^{n} g_{i j}}
$$


No quadro abaixo especifica-se a forma pela qual se classifica os setores industriais a partir resultado dos índices de ligação.

Quadro 1 - Classificação setorial segundo os índices de ligação

\begin{tabular}{ccc}
\hline Índices de ligação & ILT $>1$ & ILT $<1$ \\
\hline ILF $>1$ & Setor Chave & Dependente da demanda intersetorial \\
ILF $<1$ & Dependente da oferta intersetorial & Independente \\
\hline
\end{tabular}

Fonte: Adaptado de Miller e Blair (2009).

É interessante dizer que, quando o setor se encontra classificado como chave, isto significa que este apresenta ampla capacidade de gerar encadeamentos, tanto para trás em sua cadeia produtiva - como demandante de insumos - como para frente - como ofertante de insumos. Caso o setor seja considerado dependente da demanda intersetorial, então, pode-se dizer que este setor é um ofertante importante em sua cadeia produtiva, ou ainda, se for tido como um setor dependente da oferta intersetorial, este seria considerado como um importante demandante em sua cadeia produtiva, gerando transbordamento a montante. E por fim, caso o setor apresente ambos os índices de ligação abaixo de um, então este setor se revela como independente e possui, portanto, pouca capacidade de transbordamento produtivo.

Pela aplicação deste método será possível observar qual a abrangência do estímulo produtivo do setor de refino de petróleo sobre os demais segmentos da economia brasileira. Além disso, ao desmembrar o índice poder-se-á identificar quais são os setores que mais se beneficiam da produção de refino de petróleo, dado que o estímulo à produção neste setor não se restringe a ele próprio, mas se espraia para diversos outros.

Quanto ao multiplicador do emprego, tem-se primeiramente que calcular o coeficiente direto da variável desejada, $e_{j}=\frac{E_{j}}{X_{j}}$, que mostra para cada unidade monetária produzida pelo setor $\mathrm{j}$, o quanto se gera diretamente de emprego. Para então se obter o vetor de geração de emprego $G E=e B$. Tendo em vista este processo matemático chegase a seguinte relação

$$
M E_{j}=\frac{G E_{J}}{e_{j}}
$$

Assim, o multiplicador de emprego mostra para cada emprego gerado diretamente pelo setor $j$, quanto são gerados de forma direta e indireta. Com isso, será possível quantificar quantos empregos são gerados direta e indiretamente na economia brasileira a partir da produção de uma unidade monetária no setor de refino.

O multiplicador da produção é obtido a partir do somatório da coluna da matriz L de cada setor, ou seja,

$$
M P=\sum_{i=1}^{n} b_{i j}
$$


O resultado deste somatório indica o quanto um dado setor j, neste caso o setor de refino, ao produzir uma unidade monetária gera de transbordamento para todos os demais setores da economia de forma direta e indireta. Miller e Blair (2009) desenvolvem uma análise similar, porém acrescida do efeito induzido pelo aumento da renda, devido ao estímulo inicial a um dado setor, sobre o produto e sobre o emprego.

Este ferramental torna possível evidenciar a importância do setor sobre a estrutura produtiva do país e como seria nocivo para a economia brasileira negligenciar dentro da cadeia produtiva do petróleo o setor de refino. Destacando a sua capacidade de geração de transbordamento produtivo e, portanto, de dinamizar a economia a partir dos elos constituídos com os demais setores.

São utilizadas nesta pesquisa a matriz insumo-produto disponibilizadas pelo Instituto Brasileiro de Geografia e Estatística (IBGE) para o ano de 2015 estimada a partir do Sistema de Contas Nacionais - Referência 2010 - as quais possuem 67 setores e 127 produtos. A estrutura da matriz divulgada permite uma visão pormenorizada da estrutura produtiva brasileira e também avaliar o grau de interligação setorial da economia além dos impactos de variações na demanda final dos produtos, mediante a identificação dos diversos fluxos de produção de bens e serviços.

\subsection{Análise dos resultados}

Os resultados encontrados a partir da aplicação da metodologia exposta anteriormente encontram-se na Tabela 4 e na Tabela 5. A partir destas podem-se observar a capacidade de transbordamento - implícito nos índices de ligação -, multiplicadores de emprego e produto do setor de refino de petróleo e do setor de extração e produção de petróleo e gás.

Nas referidas tabelas é possível perceber a importância do setor de refino de petróleo e do setor de E\&P para a economia brasileira determinada por sua ampla capacidade de transbordamento de emprego e produção intersetorial. O setor de refino de petróleo aparece classificado como um setor-chave, uma vez que os encadeamentos produtivos gerados por este setor a montante e a jusante apresentaram um valor superior à média de toda a economia. Além disso, dentre os 67 setores que compõem a MIP utilizada apenas nove ${ }^{7}$ foram classificados como setores-chave no ano de 2015. Quando se compara o setor de refino com este grupo, este apresenta a maior capacidade de gerar transbordamentos produtivos intersetoriais, tanto para frente como para trás dentro de sua ampla cadeia produtiva.

A partir de seus índices de ligação constata-se que, tanto para o setor de refino como para o setor de E\&P, a capacidade de transbordamento intersetorial a jusante é

\footnotetext{
${ }^{7}$ Os setores-chave na economia brasileira no ano de 2015 e seus respectivos índices de ligações (a jusante / montante) foram: refino de petróleo (2,77 / 1,38); Fabricação de químicos orgânicos e inorgânicos, resinas e elastômeros (1,82 / 1,12); Fabricação de defensivos, desinfetantes, tintas e químicos diversos $(1,12$ / 1,10); Fabricação de produtos de borracha e de material plástico (1,19 / 1,11); Produção de ferro gusa/ferro-ligas, siderurgia e tubos de aço sem costura $(1,06 / 1,18)$; Fabricação de produtos de metal, exceto máquinas e equipamentos (1,02 / 1,08); Energia elétrica, gás natural e outras utilidades (2,01 / 1,15); transporte terrestre $(2,34$ / 1,09); Outras atividades profissionais, científicas e técnicas $(1,20$ / 1,09)
} 
superior aos seus encadeamentos gerados a montante na cadeia produtiva. Além disso, percebeu-se pela matriz de requerimento direto e indireto de insumos do setor de refino que enquanto as suas compras (coluna) se encontram mais concentradas, seu desempenho como ofertante (linha) está disperso entre diversos setores da economia. Enquanto o setor de petróleo e gás apresenta um número de demandantes e fornecedores relativamente equilibrado. Complementando a análise, a Tabela 5 mostra os setores que mais se beneficiam do aumento da produção do setor de refino e de extração e produção de petróleo e gás - setores fornecedores - e quais são os setores que ao sofrer uma expansão em sua demanda final acabam por estimular direta e indiretamente a produção de ambos setores analisados.

Tabela 4 - Índices de ligação e multiplicadores do setor de refino de petróleo brasileiro para o ano de 2015

\begin{tabular}{cccc}
\hline Setor de Refino de Petróleo & & & Classificação \\
\hline Índice de Ligação & P/ Trás & 1,37 & Setor chave \\
Multiplicadores (Efeitos diretos + indiretos) & P/ Frente & 2,77 & \\
& Produção & 2,48 & \\
Eetor de extração de petróleo e gás, inclusive & & 81 & Classificação \\
atividades de apoio & P/ Trás & 0,94 & Dependente da demanda \\
Intersetorial \\
Índice de Ligação & P/ Frente & 1,41 & \\
Multiplicadores (Efeitos diretos + indiretos) & Produção & 1,70 & \\
& Emprego & 12 & \\
\hline
\end{tabular}

Fonte: Elaboração própria a partir dos dados da Matriz Insumo-Produto disponibilizada pelo IBGE (2015).

Entende-se a partir da Tabela 5 que ambos os setores se configuram como importantes provedores da demanda intermediária da economia brasileira. Assim, uma possível queda na oferta de produtos derivados dos setores analisados- mantendo-se a demanda constante - representaria sério risco para a sustentação do crescimento da economia, uma vez que a demanda intermediária passaria possivelmente a ser atendida em grande medida por produtos importados. Isso representa um risco, também, para a sustentação do saldo da balança comercial brasileira.

É interessante observar que o principal setor estimulado pela produção de produtos derivados de petróleo é o de extração de petróleo e gás, inclusive atividades de apoio. Isto já era esperado, na medida em que é este o setor fornecedor da principal matéria prima empregada pelo setor de refino. No mais, para cada real produzido pelo setor de refino a atividade de E\&P é estimulada direta e indiretamente em $R \$ 0,41 \mathrm{em}$ 2015. 
Tabela 5 - Ranking dos principais setores demandantes e fornecedores do setor de refino de petróleo no ano de 2015

\begin{tabular}{|c|c|c|c|}
\hline \multicolumn{2}{|c|}{ Setor de refino de petróleo e coquerias } & \multicolumn{2}{|c|}{$\begin{array}{c}\text { Setor de extração de petróleo e gás, inclusive } \\
\text { atividades de apoio }\end{array}$} \\
\hline Principais demandantes ${ }^{8}$ & $\begin{array}{c}\text { Principais } \\
\text { fornecedores }\end{array}$ & Principais demandantes & $\begin{array}{c}\text { Principais } \\
\text { fornecedores }\end{array}$ \\
\hline $\begin{array}{l}\text { Refino de petróleo e } \\
\text { coquerias }\end{array}$ & $\begin{array}{l}\text { Refino de petróleo e } \\
\text { coquerias }\end{array}$ & $\begin{array}{c}\text { Extração de petróleo e gás, } \\
\text { inclusive as atividades de } \\
\text { apoio }\end{array}$ & $\begin{array}{l}\text { Extração de petróleo e } \\
\text { gás, inclusive as } \\
\text { atividades de apoio }\end{array}$ \\
\hline Transporte terrestre & $\begin{array}{l}\text { Extração de petróleo e } \\
\text { gás, inclusive as } \\
\text { atividades de apoio }\end{array}$ & $\begin{array}{c}\text { Extração de minerais } \\
\text { metálicos não ferrosos, } \\
\text { inclusive beneficiamentos }\end{array}$ & $\begin{array}{l}\text { Refino de petróleo e } \\
\text { coquerias }\end{array}$ \\
\hline Transporte aéreo & $\begin{array}{l}\text { Fabricação de } \\
\text { biocombustíveis }\end{array}$ & $\begin{array}{l}\text { Refino de petróleo e } \\
\text { coquerias }\end{array}$ & $\begin{array}{l}\text { Comércio por atacado e } \\
\text { varejo }\end{array}$ \\
\hline $\begin{array}{l}\text { Extração de minerais } \\
\text { metálicos não ferrosos, } \\
\text { inclusive beneficiamentos }\end{array}$ & $\begin{array}{l}\text { Atividades jurídicas, } \\
\text { contábeis, consultoria e } \\
\text { sedes de empresas }\end{array}$ & $\begin{array}{l}\text { Fabricação de químicos } \\
\text { orgânicos e inorgânicos, } \\
\text { resinas e elastômeros }\end{array}$ & Transporte terrestre \\
\hline $\begin{array}{l}\text { Fabricação de químicos } \\
\text { orgânicos e inorgânicos, } \\
\text { resinas e elastômeros }\end{array}$ & $\begin{array}{l}\text { Comércio por atacado e } \\
\text { varejo }\end{array}$ & $\begin{array}{l}\text { Energia elétrica, gás natural } \\
\text { e outras utilidades }\end{array}$ & Transporte aquaviário \\
\hline $\begin{array}{l}\text { Fabricação de produtos de } \\
\text { minerais não metálicos }\end{array}$ & Transporte terrestre & Transporte terrestre & $\begin{array}{l}\text { Armazenamento, } \\
\text { atividades auxiliares dos } \\
\text { transportes e correio }\end{array}$ \\
\hline $\begin{array}{l}\text { Extração de carvão mineral e } \\
\text { de minerais não metálicos }\end{array}$ & $\begin{array}{l}\text { Agricultura, inclusive o } \\
\text { apoio à agricultura e a } \\
\text { pós-colheita }\end{array}$ & Transporte aéreo & $\begin{array}{l}\text { Intermediação financeira, } \\
\text { seguros e previdência } \\
\text { complementar }\end{array}$ \\
\hline $\begin{array}{l}\text { Extração de minério de ferro, } \\
\text { inclusive beneficiamentos e a } \\
\text { aglomeração }\end{array}$ & & $\begin{array}{c}\text { Aluguéis não imobiliários e } \\
\text { gestão de ativos de } \\
\text { propriedade intelectual }\end{array}$ & $\begin{array}{l}\text { Atividades jurídicas, } \\
\text { contábeis, consultoria e } \\
\text { sedes de empresas }\end{array}$ \\
\hline \multicolumn{4}{|l|}{ Transporte aquaviário } \\
\hline \multicolumn{4}{|l|}{ Fabricação e refino de açúcar } \\
\hline $\begin{array}{c}\text { Fabricação de } \\
\text { biocombustíveis } \\
\text { Produção de ferro } \\
\text { gusa/ferroligas, siderurgia e } \\
\text { tubos de aço sem costura } \\
\text { Metalurgia de metais não } \\
\text { ferosos e a fundição de } \\
\text { metais }\end{array}$ & & & \\
\hline \multicolumn{4}{|l|}{ Outros produtos alimentares } \\
\hline \multicolumn{4}{|l|}{$\begin{array}{l}\text { Agricultura, inclusive o } \\
\text { apoio à agricultura e a pós- } \\
\text { colheita }\end{array}$} \\
\hline
\end{tabular}

\footnotetext{
${ }^{8}$ Os setores selecionados como principais demandantes foram aqueles que apresentaram um requerimento direto e indireto de insumos provenientes do setor de refino acima da média da economia.
}

\footnotetext{
${ }^{9}$ Os setores aqui selecionados como principais fornecedores foram aqueles pelos quais o setor de refino apresentou uma demanda direta e indireta superior à média, em relação ao seu requerimento intersetorial de insumos para realizar a sua produção.
} 
É possível observar que dentre todos os setores da economia brasileira o refino é aquele que apresenta o maior multiplicador de emprego. Para cada emprego diretamente gerado pelo setor gera-se outros 81 direta e indiretamente. O setor de extração de petróleo e gás, inclusive atividades de apoio é aquele que ocupa a segunda colocação quanto à dimensão do seu multiplicador de emprego que em 2015 alcançou um valor de 12, embora relevante, encontra-se aquém daquele observado no setor de refino ${ }^{10}$. Neste sentido, o estímulo à produção dos setores de refino e de E\&P apresentam impactos econômicos importantes quando se observa a capacidade de transbordamento produtivo e de emprego destes setores.

Diante do exposto pôde-se averiguar a importância destes setores na estrutura produtiva brasileira. Dentro desta perspectiva entende-se que estes setores possuem um amplo alcance em relação aos transbordamentos de emprego, produção e renda. De fato, para cada real produzido pelo setor de refino são gerados adicionais $\mathrm{R} \$ 2,48^{11}$ direta $\mathrm{e}$ indiretamente. Isto por sua vez, traz à tona a influência do refino sobre as demais atividades produtivas do país, demonstrando o poder econômico e social desta atividade. Entende-se que existe a necessidade do fortalecimento deste setor para que os benefícios gerados por este seja continuamente e crescentemente apropriado pela sociedade brasileira. Da mesma forma, para cada real produzido pelo setor de extração e produção de petróleo e gás são gerados adicionais $\mathrm{R} \$ 1,70$ na economia brasileira, reiterando a importância dos setores dentro da matriz produtiva nacional.

Deve-se observar que as atividades produtivas dos setor de refino e E\&P estão vinculadas a outros segmentos produtivos, seja industrial, agropecuário, extrativo ou de serviços, de tal modo que as decisões tomadas pela principal empresa atuante nestes setores acabam por repercutir sobre toda a economia brasileira. Entende-se que os setor de refino e E\&P é estratégico para o país e uma política em prol do adensamento da sua cadeia produtiva interna traria efeitos positivos para a economia e sociedade brasileira. $\mathrm{O}$ sucateamento do setor, redução da utilização da capacidade instalada - mesmo com aumento da demanda por derivados de petróleo - e desinvestimentos produzem efeitos severos sobre os diversos segmentos produtivos que estão direta ou indiretamente ligados à atividade de refino. A quebra de elos industriais pode ser altamente nociva, de elevado custo social e ainda irreversíveis.

Os investimentos realizados pela Petrobras na década do final da década de 2000 até 2013 se firmaram como um motor para dinamizar o crescimento do país. No entanto estas inversões sofreram uma forte redução nos anos subsequentes, principalmente no setor de refino, o qual se tornou alvo de programas de privatização. Entende-se aqui que, caso o segmento de refino seja transferido para o setor privado, nada garante que os investimentos acontecerão dentro do volume necessário, considerando o papel que ele desempenha dentro do modelo de transporte hegemônico no país, bem como no que diz respeito à pertinência desse segmento do ponto de vista socioeconômico do país, conforme os números apontados neste capítulo demonstram.

\footnotetext{
${ }^{10}$ Outro modo de observar a expressividade do valor apresentado pelo multiplicador de emprego do setor de refino e do setor de E\&P é quando se observa que o valor médio do multiplicador de emprego de todos os 67 setores presentes na MIP é de quatro.

11 É importante destacar que o setor de refino possui um multiplicador de produção superior a setores consagrados na economia brasileira, como o caso da indústria automobilística - a qual ao elevar a sua produção para atender o aumento na demanda final estimula a economia direta e indiretamente em $\mathrm{R} \$ 2,18$ - e fabricação de produtos alimentares - que apresentou um multiplicador da produção de $\mathrm{R} \$ 2,35$. Isto por sua vez, demonstra o alcance do setor de refino sobre as demais atividades produtivas dentro da economia brasileira, ficando atrás apenas do setor de abate e produtos de carne, que apresentou um multiplicador de $\mathrm{R} \$ 2,51$.
} 


\section{Considerações finais}

A petrolífera brasileira, ao longo de sua trajetória, tem assumido importante papel de indutora do desenvolvimento do país. Tal papel foi marcante durante os governos petistas. Os dados apresentados neste estudo desnudam o elevado poder de arraste, encadeamentos e geração de emprego proporcionados pela Petrobras durante os governos Lula e Dilma.

Todavia, com a deposição da presidenta Dilma Rousseff, emergiu uma nova agenda para a Petrobras. A agenda que emergiu é caracterizada pelo trinômio desinvestimentos, priorização dos acionistas e desprestígio à política de conteúdo local. A dilapidação da empresa implicará no enfraquecimento de um dos importantes mecanismos mobilizadores da economia ao alcance do Estado brasileiro, em um momento crítico para a indústria do país - marcado pela desindustrialização - e para a economia - ainda em período de recuperação pós-recessão observada nos anos de 2015 e 2016.

O pré-sal exigirá grandes investimentos associados à construção de plataformas, sistemas submarinos e infraestrutura de escoamento. Essa massa de investimentos e seu poder de encadeamento precisam ser aproveitados para fortalecer a indústria e a engenharia pesada do país. Nesse sentido, deve-se questionar as possíveis repercussões das decisões de desinvestimentos no refino anunciadas pela Petrobras sobre a economia brasileira, especialmente no que diz respeito aos elos produtivos construídos e, portanto, em relação à capacidade de gerar encadeamentos a montante e a jusante em sua cadeia produtiva. Dentro desta perspectiva, vislumbra-se a ameaça do país se tornar exportador de óleo bruto e importador de derivados, justamente quando se depara com uma oportunidade ímpar para o adensamento dessa cadeia produtiva a partir da descoberta do pré-sal.

\section{Referências}

AGÊNCIA NACIONAL DE PETRÓLEO (ANP). Avaliação da Competitividade do Fornecedor Nacional com relação aos Principais Bens e Serviços, publicação baseada em trabalho de consultoria realizado pela PUC-RJ, intitulado Mecanismos de Estímulo às Empresas Concessionárias de petróleo a adquirirem Equipamentos e serviços do Mercado Nacional, Rio de Janeiro, 1999.

AGÊNCIA NACIONAL DE PETRÓLEO (RJ) Anuário Estatístico 2018. Disponível em: $<$

https://www.google.com/url?sa=t\&rct=j\&q=\&esrc=s\&source=web\&cd=1\&ved= 2ahUKEwiF0Jvqrt_iAhUtILkGHblHDu4QFjAAegQIAxAC\&url=http\%3A\%2F $\% 2$ Fwww.anp.gov.br\%2Fimages\%2Fpublicacoes\%2Fanuarioestatistico\%2F2018\%2Fanuario_2018.pdf\&usg=AOvVaw02MrgzuFBaSm9xLU K6_sT->. Acesso em: 07 jun. 2019.

ALMEIDA, Mansueto Facundo; OLIVEIRA, Renato Lima de; SCHNEIDER, Ben Ross (2014) Política industrial e empresas estatais no Brasil: BNDES e Petrobras. Texto para Disscusão, IPEA.

BRASIL. MINISTÉRIO do Trabalho e Emprego - MTE. Relação Anual de Informações Sociais - RAIS. Brasília: disponível em <http://www.mte.gov.br/rais/default.asp>. Acesso em: 06 jun. 2019. 
DANTAS, E.; BELL, M. The co-evolution of firm-centered knowledge networks and capabilities in late industrializing countries: the case of Petrobras in the offshore oil innovation system in Brazil. World development, v. 39, n. 9, p. 1.570-1.591, Sept. 2011. Disponível em: 〈http://goo.gl/5PxQxo〉.

ECONOMÁTICA. Base de dados. Vários anos.

FURTADO, A. T., MARZANI, B. S e PEREIRA, N. M. Política de compras da indústria do petróleo e gás natural e a capacitação dos fornecedores no Brasil: o mercado de equipamentos para o desenvolvimento de campos marítimos. In: Projeto CTPETRO/ Tendência Tecnológicas, Rio de Janeiro, 2003.

GALL, N. O desafio industrial do pré-sal. O estado de S.Paulo, São Paulo, 27 mar. 2011. Disponível em: < http://goo.gl/16sy2w>.

IBGE. Pesquisa Industrial Anual. Instituto Brasileiro de Geografia e Estatística, vários anos. Disponível em: < https://www.ibge.gov.br/estatisticas/economicas/industria/9042-pesquisaindustrial-anual.html $?=\& \mathrm{t}=$ downloads $>$.

KEYNES, John Maynard. A teoria geral do emprego, do juro e da moeda. São Paulo: Ed. Atlas, 1992.

HIRSCHMAN, Albert. The strategy of economic development. New Heaven: Yale University, 1958.

MARZANI, B; FURTADO, A. T.; GUERRA, S. M. Novo contexto de abertura do mercado brasileiro de petróleo e os fornecedores locais: a criação do REPETRO. In: $2^{\circ}$ Congresso de P\&D em Petróleo \& Gás, 2003, Rio de Janeiro. Anais do $2^{\circ}$ Congresso de P\&D em Petróleo \& Gás.

MAZZUCATO, Mariana. The enterpreneurial state. Anthem Press, 2013.

MILLER, R.E; BLAIR, P.D. Input-output analysis: foundations and extensions. Englewood Cliffs, New Jersey: Prentice-Hall, Inc., 2009. 464p.

MORTARI, Valéria Silva. Evidência empíricas da importância da indústria brasileira de refino de petróleo. Dissertação de Mestrado. Programa de Pósgraduação em Economia da Universidade Federal de Uberlândia.

RAMALHO, André; Polito, Rodrigo. Parente: Conteúdo local não deve viciar indústria em reservar mercado. Valor Econômico, 22 de março de 2017. Disponível em: < https://www.valor.com.br/empresas/4909416/parente-conteudo-local-nao-deveviciar-industria-em-reservar-mercado>. Acesso em: 06 mai. 2019.

REUTERS. Conselheiro da Petrobras diz que regime de partilha é danoso ao país. Reuters, 14 de julho de 2015. Disponível em: < https://br.reuters.com/article/topNews/idBRKCNOPO2A420150714>. Acesso em: 06 mai. 2019.

SILVA, S. F. Um estudo sobre a evolução do preço de produção do petróleo nas últimas décadas. Tese de doutorado. Programa de Pós- Graduação da Universidade Federal do Rio de Janeiro. 2016.

SOUZA, N. J. Desenvolvimento econômico. São Paulo: Editora Atlas, 2008. 